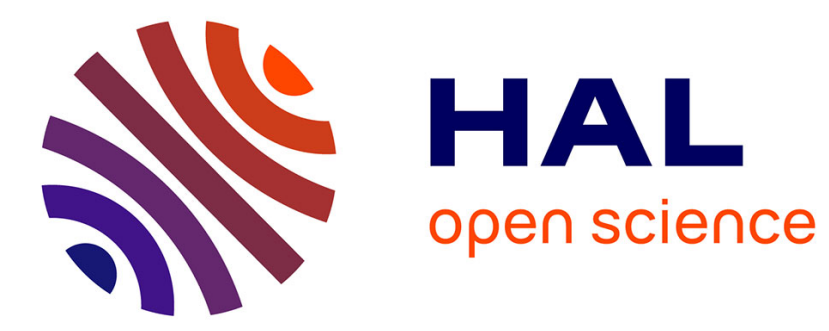

\title{
Genome-Wide Mapping of Yeast Retrotransposon Integration Target Sites
}

\author{
Anastasia Barkova, Amna Asif-Laidin, Pascale Lesage
}

\section{To cite this version:}

Anastasia Barkova, Amna Asif-Laidin, Pascale Lesage. Genome-Wide Mapping of Yeast Retrotransposon Integration Target Sites. METHODS IN ENZYMOLOGY : High-Density Sequencing Applications in Microbial Molecular Genetics, Elsevier, 2018, 10.1016/bs.mie.2018.08.002 . hal-02416741

\section{HAL Id: hal-02416741 \\ https://hal.science/hal-02416741}

Submitted on 17 Dec 2019

HAL is a multi-disciplinary open access archive for the deposit and dissemination of scientific research documents, whether they are published or not. The documents may come from teaching and research institutions in France or abroad, or from public or private research centers.
L'archive ouverte pluridisciplinaire HAL, est destinée au dépôt et à la diffusion de documents scientifiques de niveau recherche, publiés ou non, émanant des établissements d'enseignement et de recherche français ou étrangers, des laboratoires publics ou privés. 


\section{Genome-Wide Mapping of Yeast Retrotransposon Integration Target Sites}

\section{Anastasia Barkova, Amna Asif-Laidin, Pascale Lesage ${ }^{1}$}

INSERM U944, CNRS UMR 7212, Université Paris Diderot, Sorbonne Paris Cité, Institut Universitaire d'Hématologie, Hôpital St. Louis, Paris Cedex 10, France

${ }^{1}$ Corresponding author: e-mail address: pascale.lesage@inserm.fr

\section{Contents}

1. Introduction 198

2. Materials 200

2.1 Plasmid 200

2.2 Yeast Strains 205

2.3 Notes 206

3. Recovery of Independent Insertion Events 207

$\begin{array}{ll}3.1 \text { Equipment } & 207\end{array}$

$\begin{array}{ll}3.2 \text { Buffers and Reagents } & 207\end{array}$

$\begin{array}{ll}3.3 \text { Procedure } & 207\end{array}$

$\begin{array}{ll}3.4 \text { Notes } & 209\end{array}$

4. Total Genomic DNA Preparation 209

$\begin{array}{lll}\text { 4.1 DNA Extraction } & 210\end{array}$

4.2 Quality Control: Ty1 Integration PCR Assay at SUF16 212

5. De Novo Ty1 Insertion DNA Library Preparation 213

$\begin{array}{ll}5.1 \text { Equipment } & 215\end{array}$

$\begin{array}{ll}5.2 \text { Buffers and Reagents } & 215\end{array}$

$\begin{array}{ll}5.3 \text { Procedure } & 215 \\ 5.4 & 215\end{array}$

$\begin{array}{ll}5.4 \text { Notes } & 217\end{array}$

6. Data Annotation and Analysis 218

$\begin{array}{ll}6.1 \text { Tools } & 218\end{array}$

$\begin{array}{ll}6.2 \text { Procedure } & 218\end{array}$

$\begin{array}{ll}6.3 \text { Notes } & 219\end{array}$

$\begin{array}{lr}\text { 7. Concluding Remarks } & 220\end{array}$

$\begin{array}{ll}\text { Acknowledgments } & 221\end{array}$

$\begin{array}{ll}\text { References } & 221\end{array}$ 


\section{Abstract}

Transposable elements (TEs) are present in virtually all organisms. TE integration into genomes contributes to their structure and evolution, but can also be harmful in some cases. Deciphering where and how TE integration is targeted is fundamental to understand their intricate relationship with their host and explore the outcome of TE mobility on genome evolution and cell fitness. In general, TEs display integration site preference, which differs between elements. High-throughput mapping of de novo insertions by deep sequencing has recently allowed identifying genome-wide integration preferences of several TEs. These studies have provided invaluable clues to address the molecular determinants of integration site preference. Here, we provide a step-by-step methodology to generate massive de novo insertion events and prepare a library of genomic DNA for next-generation sequencing. We also describe a primary bioinformatic procedure to map these insertions in the genome. The whole procedure comes from our recent work on the integration of Ty1 in Saccharomyces cerevisiae, but could be easily adapted to the study of other TEs.

\section{INTRODUCTION}

Transposable elements (TEs) are mobile DNA sequences that play a fundamental role in shaping genomes. TEs can be deleterious in the short-term as their integration into the host genome can inactivate or deregulate gene expression. The homologous recombination between distant copies of TEs can also induce large chromosomal rearrangements (Levin \& Moran, 2011; Sultana, Zamborlini, Cristofari, \& Lesage, 2017). However, TEs have also been shown to contribute to genetic innovation (Chuong, Elde, \& Feschotte, 2016). Hence, the cell must protect its genome from TE activity, while enabling their mobility when genome diversity can be beneficial to its fate. One way to achieve this balance is to target TE insertions into regions where these elements are harmless. The sequencing of many genomes thus revealed that almost each TE family accumulates in specific regions of the genome (Sultana et al., 2017). However, their nonrandom distribution in the host genome at steady-state could be misleading since only neutral or beneficial insertions would be maintained in a longterm evolution process. It is therefore important to locate de novo insertion events to determine whether a given TE really displays integration site preferences and to analyze the underlying molecular mechanism.

The model yeasts Schizosaccharomyces pombe and Saccharomyces cerevisiae contain several families of LTR-retrotransposons (Tf1 and Tf2 in S. pombe, Ty1 to Ty5 in S. cerevisiae). These TEs replicate by reverse transcription of their 
RNA genome into a cDNA copy that is stably integrated into the host-cell genome by their own integrase. During evolution, mechanisms have emerged to avoid disruption of yeast functions by targeting integration into noncoding regions of the genome (Levin \& Moran, 2011; Sultana et al., 2017). Our knowledge of the molecular mechanisms underlying these preferences of integration comes from many studies performed in the earliest days of yeast genetics as well as recent work employing genome deep-sequencing technologies. At first, detection and mapping of de novo yeast $\mathrm{Tf}$ or Ty insertion events were based on classical molecular genetic approaches. In particular, functional elements containing a retrotransposition marker and expressed from strong inducible promoters were engineered on plasmids, to recover large number of insertion events. Then, upon digestion of genomic DNA, the junction between the retrotransposon and genomic DNA sequences could be visualized on Southern-blots or Sanger-sequenced after an inverse PCR (Behrens, Hayles, \& Nurse, 2000; Chalker \& Sandmeyer, 1990; Gai \& Voytas, 1998; Ji et al., 1993; Zou, Kim, \& Voytas, 1996; Zou, Ke, Kim, \& Voytas, 1996). Although these approaches provided important insights into the sites targeted by yeast LTR-retrotransposons, they were laborious and the low number of recovered events was generally not sufficient to obtain a complete panorama of all the targets in the genome. More recently, improved methodologies based on ligation-mediated PCR or inverse PCR amplification allowed specific enrichment of DNA fragments corresponding to de novo insertions from the bulk of host genomic DNA. These approaches, combined with next-generation sequencing (NGS) using 454 Roche or Illumina technologies, have offered the possibility to characterize thousands to millions of integration sites of retroviruses and TEs, including Tf1 in $S$. pombe and Ty1, Ty3, and Ty5 in S. cerevisiae (Baller, Gao, Stamenova, Curcio, \& Voytas, 2012; Baller, Gao, \& Voytas, 2011; Bridier-Nahmias et al., 2015; Chatterjee et al., 2014; Guo \& Levin, 2010; Jacobs et al., 2015; Qi et al., 2012). With all these studies, it has thus been possible to draw a precise profile of the integration preferences of yeast retrotransposons and the molecular mechanisms involved.

In $S$. pombe, Tf1 preferentially integrates into nucleosome-free promoters of Pol II-transcribed genes with an enrichment of stress-responsive genes (Chatterjee et al., 2014; Guo \& Levin, 2010). The DNA-binding factor Sap1 and its replication fork barrier activity collaborate to determine Tf1 target site selection (Hickey et al., 2015; Jacobs et al., 2015). In S. cerevisiae, Ty5 integrates into nucleosome-free regions at subtelomeres and silent mating-type loci (HM) through an interaction between its integrase and 
the Sir4 heterochromatin protein (Baller et al., 2011; Xie et al., 2001). In contrast, Ty3 targets the transcription start site of RNA polymerase III (Pol III)-transcribed genes through an interaction between its integrase and the Pol III transcription factors TFIIB and TFIIIC (Qi et al., 2012; Qi \& Sandmeyer, 2012). As for Ty1, its integration occurs in a narrow 1-kb window upstream of Pol III-transcribed genes (Bachmann, Eby, \& Boeke, 2004; Devine \& Boeke, 1996) and targets nucleosomal DNA, near the H2A/H2B interface (Baller et al., 2012; Mularoni et al., 2012). The primary determinant of $\mathrm{Ty} 1$ targeting to these sites remained elusive until we identified a physical interaction between Ty1 integrase and the AC40 subunit of Pol III (Bridier-Nahmias et al., 2015). High-throughput sequencing (HTS) of de novo Ty1 insertion events was not only essential to highlight the fundamental role of AC40 in Ty1 targeting to regions upstream of Pol III-transcribed genes but was also necessary to identify chromosome ends as new preferred targets of integration in the absence of AC40/integrase interaction (Bridier-Nahmias et al., 2015). This suggests that in addition to AC40, other factor(s) likely contribute(s) to Ty1 integration site selection.

The goal of this chapter is to provide a turnkey strategy that can be used by anyone aiming to address the role of additional factors in integration site selection in yeasts. For this purpose, we have taken into account the methodologies to sequence genome-wide de novo yeast retrotransposon insertion sites, recently published by several labs including ours, to set up our own protocol for Ty1 studies (Table 1). The proposed methodology combines ligation-mediated PCR and NGS using the Illumina technology.

Below, we describe step-by-step how to recover sufficient independent de novo Ty1 insertion events, prepare high-quality genomic DNA for library construction and sequencing, and finally align reads against the yeast genome to map de novo Ty1 insertions. An overview of the whole procedure is shown Fig. 1. We believe that this strategy could be easily adapted to address the molecular basis of other retrotransposon integration targeting mechanisms with minor modifications.

\section{MATERIALS}

\subsection{Plasmid}

Endogenous Ty1 copies have a low integration rate of approximately $10^{-5}$ to $10^{-7}$ per element per generation (Curcio, Lutz, \& Lesage, 2014). In order to recover a large number of de novo integration events into the cell population, it is necessary to increase Ty1 integration frequency. To this end, 
Table 1 Methodologies to Sequence Genome-Wide De Novo Yeast Retrotransposon Insertion Sites

\section{Element Authors}

Ty1 Baller et al.
(2012) Library Preparation

- pGAL1-Ty1his3AI-SCUF $2 \mu U R A 3$ plasmid with $6 \mathrm{nt}$ unique tag in the $5^{\prime} \mathrm{LTR}$

- $\mathrm{Ura}^{-} \mathrm{His}^{+}$selected colonies

- Digestion of genomic DNA with AciI or TaqI

- Ligation of adapters by PCR Sequencer and Number of Reads

- 454 Life Sciences sequencer

- For BY4741: approx. 18,000 reads out of which approx. 2000 were unambiguous

- For YPH499: approx. 90,000 reads out of which approx. 6000 were unambiguous

Mularoni et al. (2012)

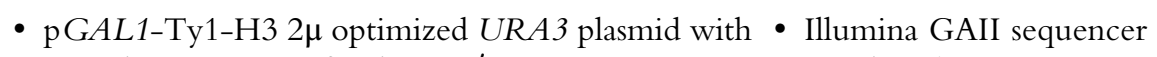
an "ssb" sequence of $25 \mathrm{bp}$ in $3^{\prime}$ LTR

- Ura ${ }^{-}$selected colonies

- Total reads: 7,990,112; nonredundant insertion sites,

- Digestion of genomic DNA with MseI and BglII

- Ligation of adapters by PCR

Bridier-Nahmias • pGAL1-Ty1his3AI-SCUF $2 \mu$ LEU2 plasmid with et al. (2015) $6 \mathrm{nt}$ unique tag in the $5^{\prime}$ LTR 38,733

- $\mathrm{His}^{+}$selected colonies

- Digestion of genomic DNA with MseI

- Ligation of adapters by PCR

Ty3 Qi et al. (2012)

- pGAL1-Ty3his3-ppt low-copy URA3 plasmid with a HIS3 gene flanked by unique 60 bp tags

- $\mathrm{Ura}^{-} \mathrm{His}^{+}$selected colonies

- Ty3 insertions amplified by inverse PCR (iPCR)
- Illumina Miseq sequencer

- Unambiguous sequences: 90,289 and 225,856 
Table 1 Methodologies to Sequence Genome-Wide De Novo Yeast Retrotransposon Insertion Sites—cont'd

\section{Element Authors}

Library Preparation

Ty5 Baller et al. (2011)

- pGAL1-Ty5his3AI centromeric URA3 plasmid

- $\mathrm{His}^{+}$selected colonies

- Digestion of genomic DNA with Acil/TaqI and MspI/HinplI

- Ligation of adapters by PCR

Tf1 Guo and Levin (2010)

- pNmt1-Tf1neo URA3 plasmid with a unique tag in U5

- $\mathrm{Ura}^{-} \mathrm{G}^{-1}{ }^{+}$selected colonies

- Digestion of genomic DNA with MseI or HpyCH4IV

- Ligation of adapters by PCR

Chatterjee et al. - pNmt1-Tf1 neo URA3 plasmid with a random $8 \mathrm{nt}$ (2014) tag in $\mathrm{U} 5$ of $5^{\prime} \mathrm{LTR}$

- $\mathrm{Ura}^{-} \mathrm{G}_{418^{+}}$selected colonies

- Digestion of genomic DNA with MseI

- Ligation of adapters by PCR

\begin{tabular}{ll}
\hline Jacobs et al. & - pNmt1-Tf1 neo URA3 plasmid $(2015)$ \\
& - Ura ${ }^{-} \mathrm{G}^{+} 18^{+}$selected colonies \\
& - Digestion of genomic DNA with MseI \\
& - Ligation of adapters by PCR
\end{tabular}

Sequencer and Number of Reads

- 454 Life Sciences sequencer

- Total of $\sim 337,000$ sequence reads, 64,000 were unambiguous (40\% of 160,000 high quality)

- 454 Life Sciences sequencer

- 599,760 reads out of which 73,152 mapped to unique positions

- Illumina GAIIx sequencer

- 1,061,068 independent integration events in WT and mutant

- Illumina Miseq sequencer 


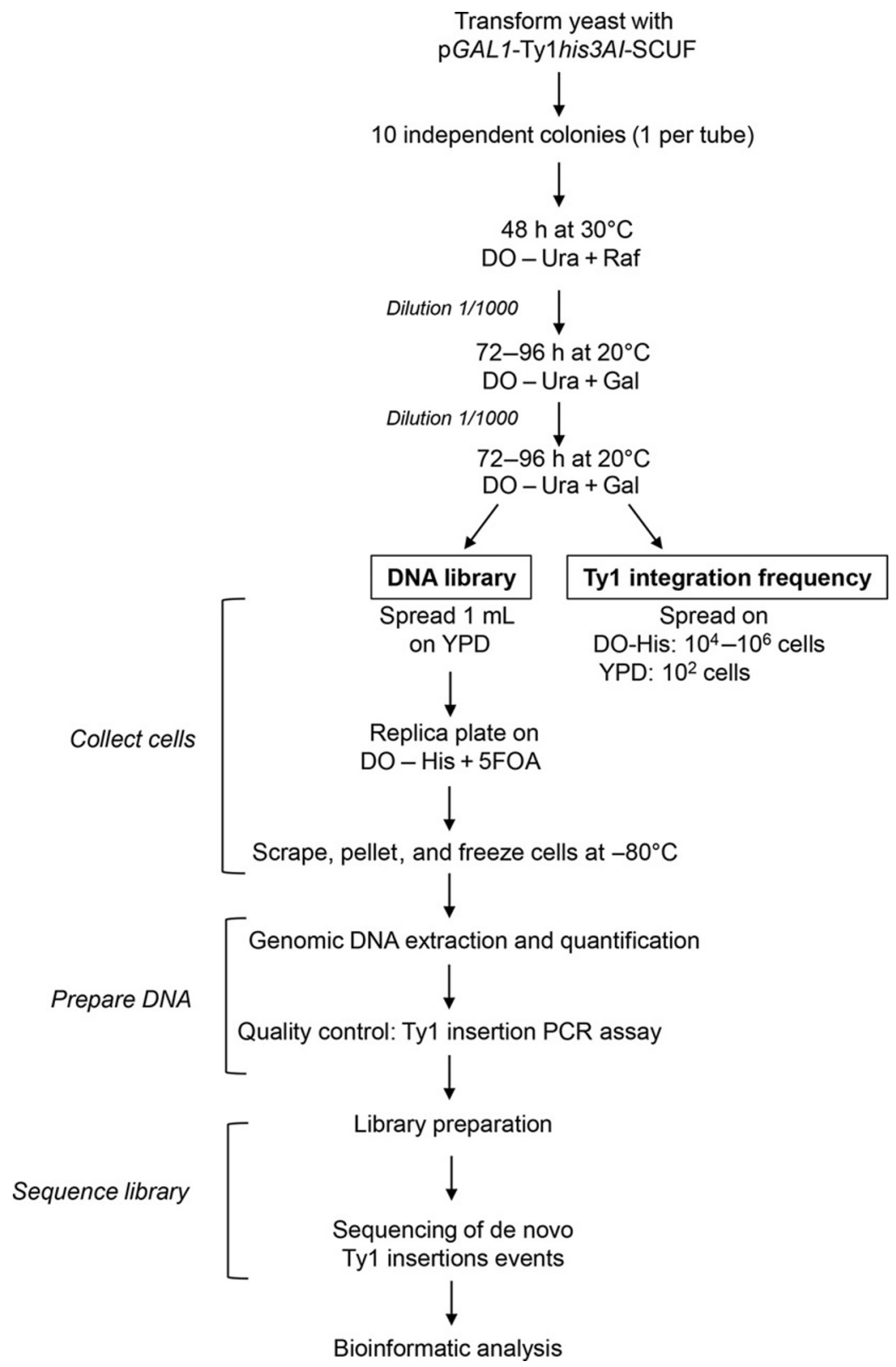

Fig. 1 Overview of the whole experimental procedure: From yeast transformation to sequencing data analysis. 
we use a high-copy number $(2 \mu)$ plasmid, pGAL1-Ty1his3AI-SCUF, which encodes the functional Ty1-H3 element from the inducible strong GAL1 promoter (Boeke, Garfinkel, Styles, \& Fink, 1985). The Ty1 sequence has been modified to contain two markers important for the recovery of de novo Ty1 insertions (Fig. 2). First, the $3^{\prime}$ untranslated region contains the retrotransposition indicator gene (RIG) his $3 A I$, which consists in the HIS3 gene in antisense orientation relative to Ty1 transcription and interrupted by an artificial intron in the sense orientation (Curcio \& Garfinkel, 1991). This construct allows functional protein synthesis from

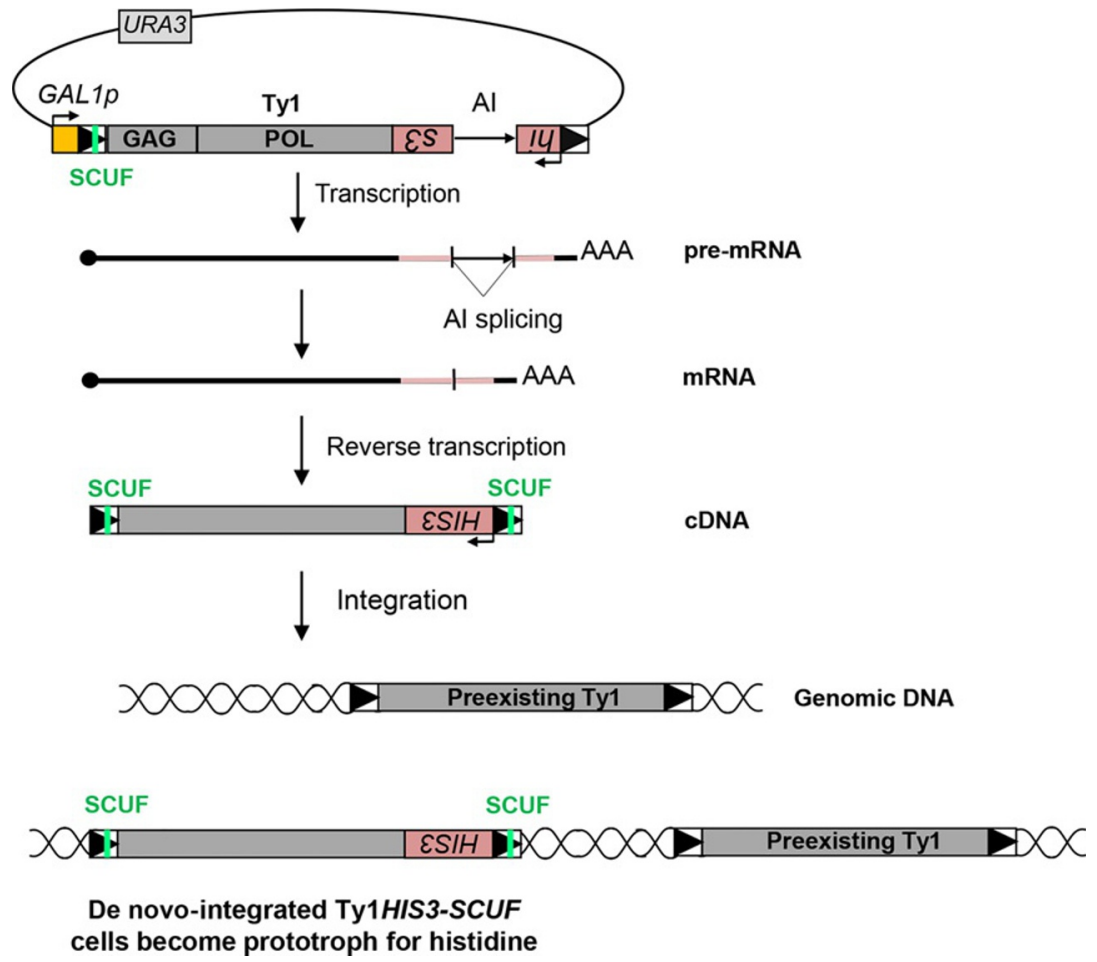

Fig. 2 pGAL1-Ty1his3Al-SCUF structure and retrotransposition assay. A $2 \mu$ plasmid carries a functional Ty1 element expressed from the galactose inducible GAL1 promoter (GAL1p, yellow box) and the URA3 selection marker (light gray box). Ty1 contains in its $3^{\prime}$ untranslated region a HIS3 gene in an antisense orientation interrupted by an intron, which is in a spliceable orientation in the Ty1 transcript (his $3 \mathrm{Al}$, pink box interrupted by a black arrow). Transcription from the $5^{\prime} \mathrm{LTR}$, splicing of Al and reverse transcription result in a Ty1 CDNA bearing a functional HIS3 gene. Integration of Ty 1 HIS3 CDNA in the yeast genome confers histidine prototrophy to $\mathrm{His}^{-}$transformants. The $5^{\prime}$ LTR harbors the SCUF sequence, which is copied in the $3^{\prime}$ LTR by reverse transcription, allowing Ty 1 de novo insertion events to be distinguished from endogenous Ty1 elements. 
HIS3 only upon reverse transcription and integration of Ty1HIS3 cDNA, thus conferring histidine prototrophy to $\mathrm{His}^{-}$cells. Therefore, cells that have undergone at least one retrotransposition event can be selected on medium lacking histidine (see Note N-2.1). Second, because it is important to discriminate de novo integration events from endogenous Ty1 elements, six nucleotides in the $5^{\prime}$ LTR of this engineered Ty1 were substituted downstream of the initiation codon of GAG ORF (Baller et al., 2012). This tag (referred to as SCUF) does not affect Gag amino acids sequence or the efficiency of Ty1 retrotransposition. Importantly, SCUF is copied by reverse transcription in the $3^{\prime} \mathrm{LTR}$, allowing to distinguish during the sequencing step the $3^{\prime}$ LTR/genomic DNA junction of de novo Ty1 insertions from the $3^{\prime}$ LTR/genomic DNA junctions of Ty1 elements preexisting in the genome (Fig. 2 and see Note N-2.2). Finally, the plasmid encoding GAL1-Ty1his3AI-SCUF construct also carries the URA3 gene that can be counter-selected in the presence of 5-fluoroorotic-acid (5FOA) (Boeke, LaCroute, \& Fink, 1984). Plasmid elimination is not essential but avoids contamination of the library of Ty1-specific amplified DNA fragments by Ty1 sequences from the plasmid (see Note N-2.3). Galactose induction of GAL1-Ty1his3AI-SCUF retrotransposition results in a frequency of $10^{-3}$ to $10^{-2} \mathrm{His}^{+}$colony/cell at $20^{\circ} \mathrm{C}$, a temperature permissive for Ty1 retrotransposition.

\subsection{Yeast Strains}

We recommend using the BY4741, BY4742 haploid strains, and the BY4743 diploid strain, which are close derivatives of the S288C laboratory strain, whose genome serves as reference in SGD (https://www. yeastgenome.org) (Brachmann et al., 1998). These strains are also the parental strains for the international systematic $S$. cerevisiae gene disruption project (Table 2). Using these strains will therefore allow aligning sequence reads of de novo insertion events on the reference genome and comparing insertions

Table 2 Recommended Yeast Strains

Strain

Name Genotype

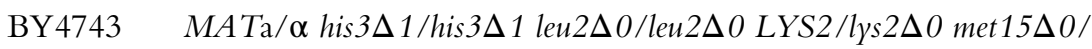
MET15 ura3 $\Delta 0 /$ ura3 $\Delta 0$

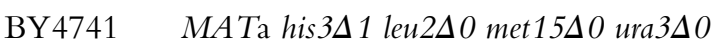

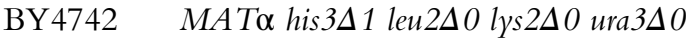


between WT and mutant strains deleted for your gene(s) of interest. Furthermore, the strains lack the HIS 3 and URA3 genes, which are auxotrophy markers important for plasmid and de novo integration events selection.

Although strain ploidy does not significantly influence targeting pattern in wild-type cells (Baller et al., 2012; Mularoni et al., 2012), it might be relevant to compare Ty1 insertion patterns in diploid and haploid cells when working with yeast mutants. If some mutants increase the number of Ty1 insertion in open reading frames, insertions in essential genes will not be recovered in haploid cells, which may result in misleading conclusions; such insertions will likely be recovered in diploid cells.

An important issue to avoid when studying the impact of Ty1 mutations on integration site selectivity is transcomplementation of Ty1 function by endogenous elements (Curcio \& Garfinkel, 1994). For this purpose, it is recommended to use spt $3 \Delta$ or ste $12 \Delta$ mutants, which prevent Ty1 transcription from its own promoter but not from GAL1 promoter (Morillon, Springer, Lesage, 2000; Winston, Durbin, \& Fink, 1984). These strains can be obtained from the Yeast Knock-Out collection (available via ATCC, Open Biosystems or Invitrogen).

\subsection{Notes}

$\mathrm{N}$-2.1. Mularoni et al. used a $\mathrm{p} G A L 1-\mathrm{Ty} 1-\mathrm{H} 3$ plasmid that contains a higher performing $2 \mu$ origin to increase the plasmid copy number, but lacks a RIG. Therefore, de novo Ty1 insertions were recovered at high frequency without selection (Mularoni et al., 2012).

$\mathrm{N}-2.2$. Alternative strategies have been developed to specifically mark de novo integration events of yeast retrotransposons (Table 1). Mularoni et al. put a tag in the $\mathrm{U} 3$ region of the $3^{\prime}$ LTR that was transferred to the $5^{\prime}$ LTR during retrotransposition of the inducible Ty1 element (Mularoni et al., 2012). For Tf1, a random sequence tag was introduced in the U5 region of the $5^{\prime}$ LTR, in order to record the numbers of independent integration events at single nucleotide positions in the genome of S. pombe (Chatterjee et al., 2014). As for SCUF, the random tag was copied in the $3^{\prime}$ LTR by reverse transcription of the element. For Ty3, two unique tags were introduced on both sides of the retrotransposon indicator HIS3 gene for amplification of integration junctions between Ty3 sequences and the flanking genome by inverse PCR (Qi et al., 2012). In the case of Ty5, no tag was added, since full-length Ty5 elements are absent in the genome of S. cerevisiae (Baller et al., 2011). 
$N$-2.3. It is possible to skip $\mathrm{p} G A L 1-\mathrm{Ty} 1$ his $3 A I-\mathrm{SCUF}$ plasmid shuffling step on 5FOA plates. In this case, however, it is necessary to eliminate sequence reads corresponding to Ty1 sequence in the plasmid from the sequencing raw data (see below).

\section{RECOVERY OF INDEPENDENT INSERTION EVENTS}

\subsection{Equipment}

- Incubator-shaker $\left(30^{\circ} \mathrm{C}\right.$ and $\left.20^{\circ} \mathrm{C}\right)$

- Spectrophotometer $(600 \mathrm{~nm})$

- Microcentrifuge

- Sterile velvets and replicate plate for Petri dishes

- Sterile plastic spreaders

\subsection{Buffers and Reagents}

- Yeast culture liquid media: Yeast Synthetic Drop-out medium (DO) lacking uracil and supplemented with raffinose $2 \%$ (DO-Ura + Raf) or $2 \%$ galactose $(\mathrm{DO}-\mathrm{Ura}+\mathrm{Gal})$

- Agar plates: Yeast peptone agar supplemented with 2\% glucose (YPD), DO agar lacking histidine and supplemented with $2 \%$ glucose (DO-His), and DO-His supplemented with 5FOA (DO-His +5 FOA). We use $50 \mathrm{mg}$ of uracil and $1000 \mathrm{mg}$ of $5 \mathrm{FOA}$ per liter of medium

- Sterile deionized water

\subsection{Procedure}

\subsubsection{Step 1: Assess Ty1 Integration Frequency to Estimate the Total Number of Cells Necessary for Library Preparation}

Under optimal conditions, pGAL1-Ty1his $3 A I-S C U F$ generates $10^{-3}$ to $10^{-2} \mathrm{His}^{+}$colonies/cell upon galactose induction at $20^{\circ} \mathrm{C}$. However, when working in a particular mutant or growth context, it is important to establish whether these conditions modify Ty1 insertion frequency. This information is crucial for library preparation, since it will determine the number of total cells to spread on plates to recover around 70,000-100,000 $\mathrm{His}^{+}$cells. Under our experimental conditions, each $\mathrm{His}^{+}$cell contains at least one Ty1HIS3 insertion, which provides a good coverage for HTS (Bridier-Nahmias et al., 2015). 1. Transform the strain(s) of interest (for example, WT and mutant strains) with pGAL1-Ty1his3AI-SCUF, select transformants on DO-Ura plates. 
2. Pick four independent colonies of each yeast transformant and inoculate in $2 \mathrm{~mL}$ of $\mathrm{DO}-\mathrm{Ura}+\mathrm{Raf}$ medium (one colony per tube: four precultures). Grow to saturation in an incubator-shaker $(180 \mathrm{rpm})$ at $30^{\circ} \mathrm{C}$ overnight.

3. Dilute each preculture 1000 -fold in $3 \mathrm{~mL}$ of $\mathrm{DO}-\mathrm{Ura}+\mathrm{Gal}$ and grow cell cultures to induce retrotransposition in an incubator-shaker at $20^{\circ} \mathrm{C}$ for $3-4$ days depending on the strain (9-10 generations) (see Note N-3.1).

4. Spread $10^{2}$ cells on YPD and $10^{4}, 10^{5}$, and $10^{6}$ cells on DO - His (For WT cells, one DO - His plate with $10^{5}$ cells is sufficient). Incubate $2-3$ days at $30^{\circ} \mathrm{C}$. Count colonies on plates and then determine the integration frequency by dividing the total number of histidine prototroph colonies by the total number of colonies on YPD.

5. Determine from the observed frequency the number of total cells necessary to obtain 70,000-100,000 $\mathrm{His}^{+}$cells.

\subsubsection{Step 2: Collect Cells Containing De Novo Ty1HIS3 Insertions}

1. Pick 10 independent colonies of each yeast transformant (for example, 10 of WT and 10 of mutant transformants) and inoculate in $2 \mathrm{~mL}$ of $\mathrm{DO}-\mathrm{Ura}+$ Raf medium (one colony per tube: 10 precultures per yeast transformant). Grow to saturation the 10 cultures in an incubator-shaker (180 RPM) at $30^{\circ} \mathrm{C}$ overnight (see Note $\mathrm{N}-3.2$ ).

2. Dilute each culture 1000 -fold in $3 \mathrm{~mL}$ of DO - Ura + Gal and grow cell cultures to induce retrotransposition in an incubator-shaker at $20^{\circ} \mathrm{C}$ for 3-4 days depending on the strain (9-10 generations). Keep one culture of WT transformant grown in DO - Ura + Raf at $30^{\circ} \mathrm{C}$, which genomic DNA will serve as control in step 2 of Section 4.2.3.

3. Dilute each culture one more time 1000 -fold in $3 \mathrm{~mL}$ of DO - Ura $+\mathrm{Gal}$ and grow cell cultures for $3-4$ days at $20^{\circ} \mathrm{C}$ to increase the recovery of independent de novo insertion events.

4. When cultures are saturated, spread $1 \mathrm{~mL}$ of (see Note N-3.3) of each culture on a YPD plate to allow spontaneous loss of plasmid. Incubate $24 \mathrm{~h}$ at $30^{\circ} \mathrm{C}$. In parallel, do a frequency assay for every culture as described in Step 1 (no. 4) to further discard cultures with abnormal retrotransposition frequency (see Note N-3.4).

5. Replica plate the lawn of cells obtained on YPD plates on DO-His $+5 \mathrm{FOA}$ with sterile velvets. As the plasmid contains the URA3 gene, 5FOA will be toxic for cells that have not lost the plasmid. 
6. After 2-3 days, add $1 \mathrm{~mL}$ of sterile deionized water on the plates and scrape the cells ( $\mathrm{His}^{+} \mathrm{Ura}^{-}$) with a plastic spreader. Transfer the cells to $2-\mathrm{mL}$ tubes. Wash the plates again with $0.5 \mathrm{~mL}$ of sterile deionized water and transfer the remaining cells to the same tubes.

7. Centrifuge $5 \mathrm{~min}$ at $6000 \mathrm{rpm}$. Wash the cells with $1.5 \mathrm{~mL}$ of sterile deionized water.

8. Centrifuge $5 \mathrm{~min}$ at $6000 \mathrm{rpm}$. Suspend the cell pellets in $1.5 \mathrm{~mL}$ of sterile deionized water and split the samples into two 1.5-mL tubes. Centrifuge again and remove supernatant.

9. Freeze cell pellets at $-80^{\circ} \mathrm{C}$ until total genomic DNA extraction (see Note N-3.5).

\subsection{Notes}

N-3.1. Although the standard growth temperature for yeast is $30^{\circ} \mathrm{C}, \mathrm{Ty} 1$ retrotransposition is much more efficient at $20-22^{\circ} \mathrm{C}$.

$N-3.2$. Ten independent cultures limit the impact of insertion events occurring early in cell culture on the library diversity.

$N-3.3$. If Ty1 integration frequency is low in your experimental condition, it is necessary to adjust the volume of culture to spread on YPD in order to have at least $10^{4} \mathrm{His}^{+}$colonies per culture to scrape from $\mathrm{DO}-$ His plates (meaning that there are at least $10^{4}$ integration events, independent or not). If working with a mutant that decreases Ty1 integration frequency, we recommend using larger Petri dishes (diameter, $144 \mathrm{~mm})$ to spread more cells.

$\mathrm{N}-3$.4 It could happen that a transformant displays a very low $\mathrm{His}^{+}$colony/cell frequency due to recombination between the two LTR of GAL1-Ty1his3AI-SCUF. This clone must be discarded for the library preparation.

N-3.5. Two pellets of approximately $0.5 \times 10^{4}$ cells are collected for each transformant. One is used for further steps and the other one is kept as a backup at $-80^{\circ} \mathrm{C}$ until the de novo insertion libraries have been validated.

\section{TOTAL GENOMIC DNA PREPARATION}

To obtain total genomic DNA, we perform a phenol-chloroform extraction according to classical procedures (Adams, Gottschling, Kaiser, \& Stearns, 1997) followed by fluorometric DNA quantification to calculate the exact double strand DNA (dsDNA) concentration in each sample. 
Ty1 integrates mainly within a 700 base pair window upstream of tRNA genes (Baller et al., 2012; Bridier-Nahmias et al., 2015; Mularoni et al., 2012). This can be easily observed in a dedicated PCR that monitors Ty1 integration upstream of the SUF16 tRNA gene, a known target of integration (Nyswaner, Checkley, Yi, Stephens, \& Garfinkel, 2008). Resolved on agarose gel, the PCR pattern is characterized by a ladder-like banding profile of several bands corresponding to two insertions per nucleosome. This assay is useful to discard any genomic DNA from a clone that exhibits an abnormal integration profile compared to the other samples of the same transformant as it could distort your sequencing analysis (Fig. 3). This discrepancy is exceptional but could happen by spontaneous reversion of a mutant phenotype in one clone.

\subsection{DNA Extraction}

\subsubsection{Equipment}

- Fluorometer (Qubit ${ }^{\mathrm{TM}}$ )

- Centrifuge

- Vortex (Disruptor Genie ${ }^{\circledR}$, VWR)

\subsubsection{Buffers and Reagents}

- Phenol:Chloroform:Isoamyl Alcohol (Sigma 77617)

- Chloroform

- DNA Lysis Buffer (2\% Triton X-100, 1\% SDS, $100 \mathrm{mM} \mathrm{NaCl}, 10 \mathrm{mM}$ Tris- $\mathrm{HCl}$ ( $\mathrm{pH} 8$ ), $1 \mathrm{mM} \mathrm{Na} 2$ EDTA)

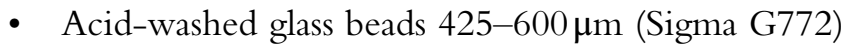

- EtOH 100\% and EtOH 70\%

- TE+RNase $\left(10 \mathrm{~m} M\right.$ Tris-HCl pH 8, $1 \mathrm{~m} M \mathrm{Na}_{2}$ EDTA, RNase A $10 \mathrm{mg} / \mathrm{mL}$ )

- Qubit $^{\mathrm{TM}}$ dsDNA BR assay kit (Thermo Fisher Q32853)

\subsubsection{Procedure}

1. Total genomic DNA is extracted from the cell pellets of the 10 independent cultures of each yeast transformant.

2. Add $300 \mu \mathrm{L}$ glass beads, $200 \mu \mathrm{L}$ of DNA lysis buffer, and $200 \mu \mathrm{L}$ of phenol:chloroform:isoamyl alcohol to each cell pellet.

3. Vortex with disruptor for $5 \mathrm{~min}$ at $4^{\circ} \mathrm{C}$ (see Note $\mathrm{N}-4.1$ ).

4. Centrifuge at $10,000 \mathrm{rpm}$ for $10 \mathrm{~min}$ at $4^{\circ} \mathrm{C}$.

5. Collect the aqueous phase (approx. $150 \mu \mathrm{L}$ ). Avoid the contact with white layer. 
A

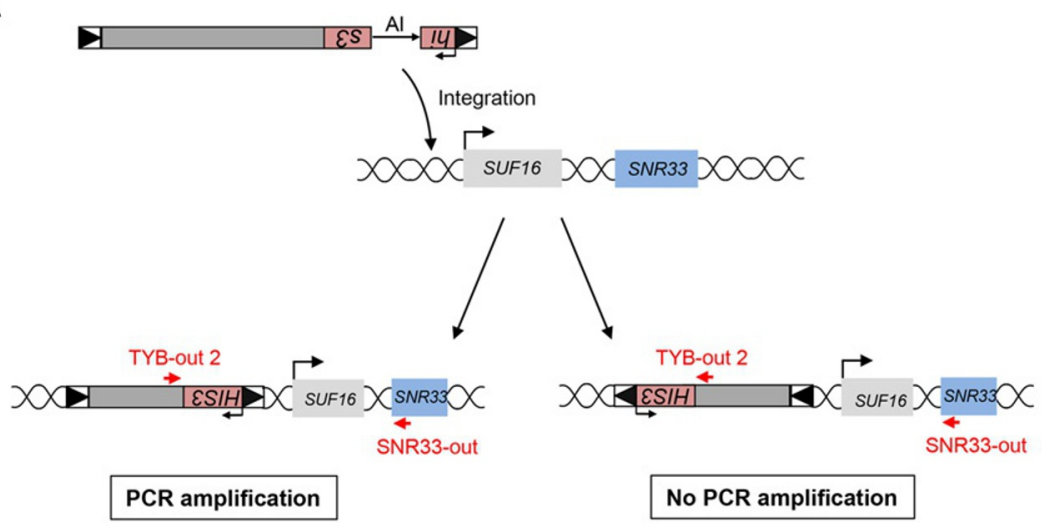

B

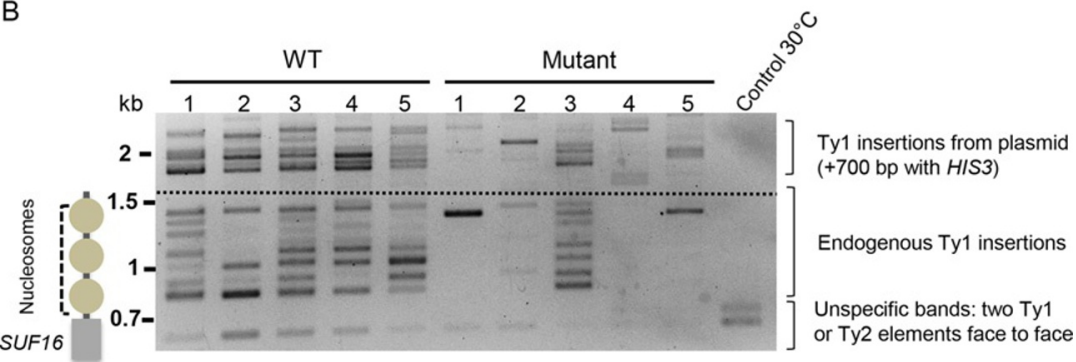

Fig. 3 Ty1 integration PCR assay at SUF16: Quality control. (A) Experimental design. PCR reactions are carried out with primers SNR33-out and TYB-out 2 (arrowheads). Only Ty1HIS3 inserted in one direction are amplified by this PCR assay. (B) Example of a PCR assay resolved on agarose gel. PCR reaction was performed on extracted genomic DNA of five wild-type (WT) and five mutant yeast transformants grown in DO - Ura + Gal at $20^{\circ} \mathrm{C}$ and one WT yeast transformant grown in DO - Ura + Raf at $30^{\circ} \mathrm{C}$ (control $30^{\circ} \mathrm{C}$ ). On the top of the gel, the bands correspond to de novo insertions of Ty1HIS3 cDNA coming from GAL1-Ty1his3AI-SCUF retrotransposition. In the middle of the gel, the bands correspond to de novo insertions of endogenous Ty1 elements. In WT cells, the apparent periodic banding patterns observed for Ty1HIS3 and Ty1 de novo insertion events results from two integrations per nucleosome on the first three nucleosomes upstream of SUF16 (Baller et al., 2012; Mularoni et al., 2012). In the mutant context, the periodic pattern is altered except for mutant \#3, which displays a WT profile, suggesting mutant phenotype reversion. This DNA was discarded and not used for further library construction. In all samples, one or two extra bands are detected below the minimum size expected for de novo insertion events (bottom of the gel). These bands correspond to the amplification of Ty1 and closely related Ty2 endogenous copies located face to face in the yeast genome. 
6. Repeat once the extraction by adding one volume of phenol:chloroform:isoamyl alcohol. Vortex $10 \mathrm{~s}$. Centrifuge at $10,000 \mathrm{rpm}$ for $10 \mathrm{~min}$ at $4^{\circ} \mathrm{C}$ and collect the aqueous phase.

7. Add one volume of chloroform. Vortex $10 \mathrm{~s}$. Centrifuge at $10,000 \mathrm{rpm}$ for $10 \mathrm{~min}$ at $4^{\circ} \mathrm{C}$ and collect the aqueous phase.

8. Add 2.5 volume of $\mathrm{EtOH} 100 \%$ to precipitate the DNA, mix five times by inversion, and centrifuge at $10,000 \mathrm{rpm}$ for $10 \mathrm{~min}$ at $4^{\circ} \mathrm{C}$.

9. Wash the pellet with $500 \mu \mathrm{L} \mathrm{EtOH} \mathrm{70 \% .} \mathrm{Do} \mathrm{not} \mathrm{vortex} \mathrm{to} \mathrm{protect} \mathrm{the}$ pellet. Centrifuge at $10,000 \mathrm{rpm}$ for $10 \mathrm{~min}$ at $4^{\circ} \mathrm{C}$.

10. Air-dry for $5 \mathrm{~min}$ at $50^{\circ} \mathrm{C}$.

11. Suspend the pellet in $100 \mu \mathrm{L} \mathrm{TE}+\mathrm{RN}$ ase. Incubate $15 \mathrm{~min}$ at $42^{\circ} \mathrm{C}$ to degrade RNAs.

12. Measure the extracted genomic DNA concentration with the fluorometer following the instructions provided by the manufacturer (see Note N-4.2).

13. The extracted genomic DNA can be conserved at $-20^{\circ} \mathrm{C}$, until the de novo insertion libraries have been validated.

\subsection{Quality Control: Ty1 Integration PCR Assay at SUF16}

\subsubsection{Equipment}

- Thermocycler

- Electrophoresis system

\subsubsection{Buffers and Reagents}

- Phusion $^{\mathrm{TM}}$ High-Fidelity DNA polymerase $(2 \mathrm{U} / \mu \mathrm{L})$ and Green $\mathrm{HF}$ Buffer (Thermo Fisher F530S)

- Fresh dNTPs $10 \mathrm{~m} M$ solution (avoid thaw/freeze)

- DNase/RNase-free sterile water (Sigma W4502-1L)

- Extracted genomic DNA and PCR primers

- UltraPure ${ }^{\mathrm{TM}}$ agarose (Thermo Fisher 16500500)

\subsubsection{Procedure}

1. Primers used for the PCR reaction are located in Ty1 sequence upstream of his 3AI in GAL1-Ty1his3AI-SCUF and in SNR33, a gene located downstream of the SUF16 tRNA gene (Dakshinamurthy, Nyswaner, Farabaugh, \& Garfinkel, 2010; Mou, Kenny, \& Curcio, 2006) (Table 3). Ty1 insertion occurs with equal frequency in both orientations (Baller et al., 2012; Mularoni et al., 2012). These primers will 
Table 3 Primers for PCR Assay

Primer

Name Sequence

\section{Coordinates}

TYB-out 2 5'-GTGATGACAAAACCTCTTCCG-3' Ty1-H3: 5,500-5,200

SNR33-out 5'-TTTTAGAGTGACACCATCGTAC-3' Chr III:

$142,507-142,528$

only amplify Ty1 insertions in the direct orientation upstream of SUF16 (Fig. 3A).

2. Set up the PCR reaction for Phusion DNA Polymerase in $25 \mu \mathrm{L}$ of total volume, for each genomic DNA of the 10 independent cultures. As control, use genomic DNA from a transformant grown in DO - Ura + Raf at $30^{\circ} \mathrm{C}$. Final concentrations in the reaction mix should be: Phusion Green HF Buffer $1 \times$, dNTPs $200 \mu M$, primers TYB-out 2 and SNR33-out $0.5 \mu M$ each, Phusion 0.5 units and genomic DNA 30 ng. Complete with DNase/RNase-free water.

3. Run PCR as follows: $2 \mathrm{~min}$ at $98^{\circ} \mathrm{C}, 10 \mathrm{~s}$ at $98^{\circ} \mathrm{C}, 30 \mathrm{~s}$ at $61^{\circ} \mathrm{C}, 1 \mathrm{~min}$ at $72^{\circ} \mathrm{C}$ ( 30 cycles), $5 \mathrm{~min}$ at $72^{\circ} \mathrm{C}$.

4. Run $1.5 \%$ agarose gel at $100 \mathrm{~V}$ with $12.5 \mu \mathrm{L}$ of PCR reaction.

5. Compare the PCR pattern on gel and discard clone(s) that exhibits an abnormal profile compare to the other clones from the same yeast transformant (Fig. 3B).

\subsubsection{Notes}

$N$-4.1. Another possibility is to break cells with a MagNA Lyser ${ }^{\mathrm{TM}}$ (Roche), which provides in general higher yields of extracted genomic DNA.

N-4.2. Contrary to the commonly used spectrophotometer Nanodrop, the fluorometer will measure only dsDNA by quantifying the fluorescent molecules specifically bound to dsDNA. Importantly, we did not notice any correlation between dsDNA concentration measured by Nanodrop and fluorometer. We generally obtain a concentration of 30-100 ng of dsDNA/ $\mu \mathrm{L}$ for each sample.

\section{DE NOVO TY1 INSERTION DNA LIBRARY PREPARATION}

Here, we describe the protocol to prepare a library of Ty1 insertion events for HTS, adapted from supplementary material of Bridier-Nahmias 


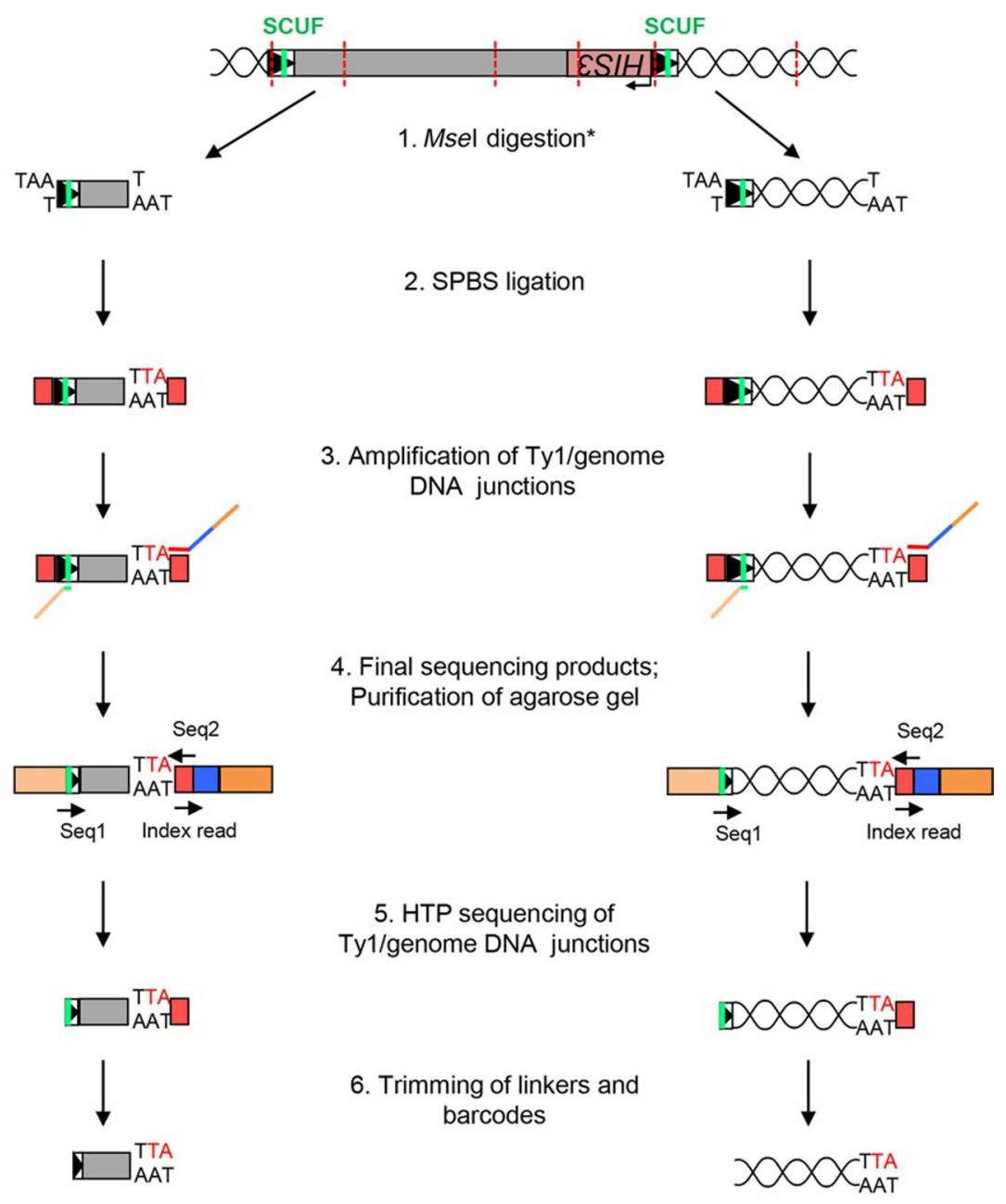

Ty1 discarded reads

De novo Ty1 insertion reads

Fig. 4 Custom de novo Ty1 insertion library. After the induction of GAL1-Ty1 his3Al-SCUF retrotransposition and recovery of $\mathrm{His}^{+}$cells, genomic DNA is extracted and digested with Msel (T/AAT) that cuts approximately every $200 \mathrm{bp}$. The alternative is to shear DNA by sonication (indicated by a star). A sequence primer-binding site (SPBS, in red) with an Msel compatible extremity (TA overhang) is ligated to Msel-digested DNA. Next, Illumina adapters are added at both extremities by PCR amplification. One primer contains the $5^{\prime}$ Illumina adapter sequence (light orange) and the SCUF sequence (green), while the other one contains the SPBS sequence (red) and index tag (blue) to distinguish reads from different strain backgrounds (i.e., WT vs mutant) and the $3^{\prime}$ Illumina adapter (orange). After PCR amplification, DNA fragments between 300 and $700 \mathrm{bp}$ are purified on agarose gel and sequenced with Seq 1 and Seq 2 primers with Illumina sequencer. Then, reads that passed quality control, and corresponding to $3^{\prime}$ LTR-SCUF, are aligned to the yeast genome. 
et al. (2015) and presented in Fig. 4. Only total genomic DNA of clones that have passed the different quality controls (integration frequency and PCR assay, described in Sections 3.3 and 4.2.3) will be used for the library preparation (see Note $N-5.1$ ).

\subsection{Equipment}

- Thermocycler

- Speedvac

- UV transilluminator

- Dry bath

- Fluorometer (Qubit ${ }^{\mathrm{TM}}$ )

\subsection{Buffers and Reagents}

- Extracted genomic DNA

- MseI restriction enzyme (New England Biolabs)

- Nucleospin gel and PCR clean-up kit (Macherey-Nagel)

- Sequencing Primer Binding Site (SPBS)

- $\mathrm{NaCl} 100 \mathrm{mM}$

- T4 DNA ligase (New England Biolabs)

- Illumina adapters

- Phusion High-Fidelity DNA polymerase $(2 \mathrm{U} / \mu \mathrm{L})$

- Electrophoresis system

\subsection{Procedure}

1. Digest DNA. $500 \mathrm{ng}$ of each of the 10 genomic DNA extracts from the same yeast DNA transformant are pooled together and digested in five independent enzymatic reactions with $\mathrm{Mse}$ I $(10 \mu \mathrm{L}$ NEB Buffer $2,1 \mu \mathrm{g}$ of genomic DNA per reaction, complete with DNase/RNase-free sterile water to $100 \mu \mathrm{L}$ ) overnight at $37^{\circ} \mathrm{C}$ (see Note N-5.2).

2. Pool the five digestions of the same strain and purify on one PCR clean-up column (Macherey-Nagel). Elute in $50 \mu \mathrm{L}$ of DNase/RNase-free sterile water and determine concentration with fluorometer.

3. Prepare SPBS. SPBS dsDNA oligonucleotide contains a TA overhang necessary for its ligation to $M s e I-$ digested genomic DNA. Anneal equal amounts $(5 \mu \mathrm{L})$ of SPBS-primer 1 and SPBS-primer $2(100 \mu \mathrm{M})$ in $100 \mu \mathrm{L} \mathrm{NaCl} 100 \mathrm{~m} M$ (Table 4). First, denature primers at $100^{\circ} \mathrm{C}$ for 5 min in a dry bath, then let the primer mix cool slowly by placing on the bench the dry bath block heater for $3 \mathrm{~h}$. Determine dsDNA concentration with a fluorometer. 
Table 4 Primers Used to Construct Ty1 De novo Insertion Library

\section{Remarks}

SPBS-primer 1 5'TAACATCGAGATCGGAAGAGCACACGTCTGAA Underlined: complementary SPBS sequence. At the 5' CTCCAGTCA $3^{\prime}$ end, the TA overhang is necessary for ligation to $M s e I-$ digested genomic DNA

\begin{tabular}{|c|c|c|}
\hline SPBS-primer 2 & $\begin{array}{l}5^{\prime} \text { GTGACTGGAGTTCAGACGTGTGCTCTTCCG } \\
\text { ATCTCGATGT }^{\prime}\end{array}$ & Underlined: complementary SPBS sequence \\
\hline P5-SCUF & $\begin{array}{l}5^{\prime} \text { aatgatacggcgaccaccgagACTCGAATCGCAACAGCT } \\
\text { TAGC3 }^{\prime}\end{array}$ & $\begin{array}{l}\text { Sequencing adapters that binds specifically to SCUF } \\
\text { in Ty1 and has P5 Illumina adapter. Uppercase, } \\
\text { SCUF-binding sequence; lowercase, P5 Illumina } \\
\text { adapter sequence; underlined, six nucleotide } \\
\text { substitutions defining SCUF }\end{array}$ \\
\hline $\begin{array}{l}\text { P7-index tag- } \\
\text { SPBS }^{\text {a }}\end{array}$ & $\begin{array}{l}5^{\prime} \text { CAAGCAGAAGACGGCATACGAGATATCACG } \\
\text { agatcggaagagcacacgtct } 3^{\prime}\end{array}$ & $\begin{array}{l}\text { Sequencing adapters that binds specifically to SPBS and } \\
\text { has P7 Illumina adapter and index tag. Uppercase, } \\
\text { SPBS-binding sequence; lowercase, P7 Illumina } \\
\text { sequence; underlined, Illumina index tag (index tags } \\
\text { allow multiplex sequencing of different libraries) }\end{array}$ \\
\hline Seq1 & $\begin{array}{l}\text { GGAATCCCAACAGCTTAGCCAACATTCACCCA } \\
\text { TTTCTCA }\end{array}$ & $\begin{array}{l}\text { Primer "read } 1 \text { " for sequencing, complementary to } 3 \text { ' } \\
\text { LTR of Ty1. Underlined, SCUF sequence }\end{array}$ \\
\hline Seq2 & $\begin{array}{l}\text { AGATCGGAAGAGCACACGTCTGAACTCCAG } \\
\text { TCAC }\end{array}$ & $\begin{array}{l}\text { Primer "read 2" for sequencing. Complementary to } \\
\text { SPBS }\end{array}$ \\
\hline Index read & $\begin{array}{l}\text { GTGACTGGAGTTCAGACGTGTGCTCTTCCG } \\
\text { ATCT }\end{array}$ & $\begin{array}{l}\text { Primer for sequencing to read the index tag. } \\
\text { Complementary to SPBS }\end{array}$ \\
\hline
\end{tabular}

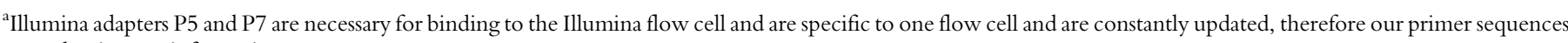
are only given as information. 
4. PCR-mediated ligation of Illumina-sequencing adapters and amplification of $T y 1 /$ genomic DNA junctions. Use $650 \mathrm{ng}$ of digestion product and $600 \mathrm{ng}$ $(3,3 \mu \mathrm{L})$ (see Note $N-5.3)$ of annealed SPBS in $200 \mu \mathrm{L}$ reaction $(10 \mu \mathrm{L}$ NEB T4 DNA ligase, $20 \mu \mathrm{L}$ Ligase Buffer $10 \times$, complete with DNase/ RNase-free sterile water). Divide the reaction mixture in 10 PCR tubes $\left(20 \mu \mathrm{L}\right.$ per tube) and incubate at $16^{\circ} \mathrm{C}$ overnight in a thermocycler.

5. Pool and purify the ligation mixture on a PCR clean-up column (Macherey-Nagel) and elute in $30 \mu \mathrm{L}$. Use one column for the 10 tubes containing genomic DNA of the same yeast transformant. Determine dsDNA concentrations with a fluorometer.

6. PCR amplification of TY1 insertion sites and binding of sequencing adapters. For each yeast transformant genomic DNA, perform 10 PCR reactions in parallel with Phusion DNA polymerase to amplify $50 \mathrm{ng}$ of purified ligation product in a final volume of $50 \mu \mathrm{L}$ per tube. Final concentrations should be: Phusion HF buffer $1 \times$, dNTPs $200 \mu M$, primers (P5-SCUF and P7-index tag-SPBS) $0.5 \mu M$ each, Phusion 0.5 units and complete with DNase/RNase-free water to $50 \mu \mathrm{L}$ (Table 4). Run PCR as follows: 30 s $98^{\circ} \mathrm{C}, 10$ s $98^{\circ} \mathrm{C}, 30$ s $68^{\circ} \mathrm{C}, 30$ s $72^{\circ} \mathrm{C}$ (14-18cycles), 5 min $72^{\circ} \mathrm{C}$ (see Note N-5.4).

7. Concentrate PCR-amplified $D N A$. For each yeast transformant, pool the $10 \mathrm{PCR}$ reactions in one $1.5-\mathrm{mL}$ tube and use a Speedvac at $30^{\circ} \mathrm{C}$ for approximately $1 \mathrm{~h} 30 \mathrm{~min}$. Concentrate the DNA to $50 \mu \mathrm{L}$ final volume.

8. Gel purification of the DNA-sequencing library. Load the $50 \mu \mathrm{L}$ of DNA on a $1.5 \%$ agarose gel, migrate at $100 \mathrm{~V}$. Stain gel with EtBr. Cut out the large smear of DNA fragments present between 300 and $700 \mathrm{bp}$ and purify DNA fragments on gel clean-up column (Macherey-Nagel).

9. The prepared library is ready to be sequenced. Measure DNA concentration with fluorometer. The amount of DNA required for sequencing will depend on the Illumina sequencer.

\subsection{Notes}

N-5.1. Some companies specialized in NGS, such as Fasteris (Switzerland), have now developed strategies for de novo transposon insertion sequencing. These companies have reliable and reproducible protocols for the sequencing library preparation.

$N-5.2$. When the genomic DNA is cut with a single restriction enzyme, all the sequenced fragments start with the same first nucleotides. This will not generate enough diversity in the DNA extremities leading to 
sequencing errors. To overcome this problem, one possibility is to digest DNA with a cocktail of restriction enzymes (Baller et al., 2011) or to shear it by sonication, a strategy that we have privileged.

$N-5.3$. SPBS-primer 1 and SPBS-primer 2 have a molecular weight of 11,073 and $10,430 \mathrm{~g} / \mathrm{mol}$, respectively.

N-5.4. It is recommended to perform as few PCR cycles as possible for each reaction in order to avoid PCR amplification errors. For more information on PCR biases, see Van Dijk, Jaszczyszyn, and Thermes (2014).

\section{DATA ANNOTATION AND ANALYSIS}

The following section describes how to filter Illumina sequencing raw data to obtain reads specific for de novo Ty1 insertion events and map them to reference genome. All the tools and parameters proposed are those we use in the lab and are given as example. Everyone can choose to run the tools they prefer or set different options.

\subsection{Tools}

FastQC: http://bioinformatics.babraham.ac.uk/projects/fastqc

Cutadapt: http://cutadapt.readthedocs.io/en/stable/index.html

BWA: http://bio-bwa.sourceforge.net

ggplot2: http://ggplot2.tidyverse.org

\subsection{Procedure}

1. Reads are recovered into Fastq format from Illumina sequencer.

2. Make a quality control of the reads with FastQC.

3. If FastQC reports low-quality reads, trim sequence ends with Cutadapt, since sequencing errors come generally from sequences extremities.

4. Remove the sequencing adapters sequences with Cutadapt.

5. Run again FastQC to compare the processed sequence data file with the raw one. Make sure that you reached a good quality level (see Note N-6.1).

6. Remove reads starting with $5^{\prime}$ LTR-SCUF and ending in Ty1 GAG sequences (see Note $N-6.2$ ).

7. Map the reads with the aligner of your choice (Bowtie 2, BWA, ...). We chose to align our reads using BWA-MEM (Li \& Durbin, 2009) to the yeast reference genome (S288C release 64-2-1 available at SGD) for paired-end reads with default options. This will generate a SAM file. 
Users can set alignment options depending on their sequenced data and the quality they desire.

8. Only properly aligned paired-end reads, SAM FLAG 83 (reverse) and 99 (forward) are retained (see Note N-6.3).

9. SAM file needs to be cleaned from extra information, thus only data for the FLAG with orientation (reverse or forward), chromosome, start and end position, and read sequence are conserved.

10. Duplicated reads are discarded: same orientation, same start and end positions (see Note N-6.4).

11. The number of reads obtained here is the number of de novo insertion events in the sequenced yeast population. Those reads represent approx. $5 \%$ of the total aligned reads. This cleaned file can be used for further downstream analysis.

12. To count the number of reads for every genomic position, the reads with same start position and orientation are added up. This number is indicated in a new column.

13. ggplot 2 is used to make graphic visualization. The $y$-coordinate is the number of reads at each position and the $x$-coordinate the position of the read on the chromosome.

\subsection{Notes}

N-6.1. Raw reads quality has to be checked before the alignment. Sequencer can make mistakes particularly at the end of the reads. Trimming is done to cut the low-quality reads. Sometimes there can be also contamination with adapters or others sequences. FastQC is an easy and fast way to control quality.

N-6.2. Some reads correspond to the $5^{\prime} \mathrm{LTR}-\mathrm{SCUF}$ and GAG Ty1 sequence (Fig. 4). These reads must be filtered from your dataset with a homemade script.

N-6.3. SAM file has a precise nomenclature. SAM FLAG represents the quality score of the mapped read. More information is available at http:// samtools.sourceforge.net.

N-6.4. During sequencing library preparation, PCR amplification of Ty1/genomic DNA junctions (step 4 in Section 5.3) may overproduce a subpopulation of DNA fragments. This will bias interpretation of sequencing data by increasing the number of reads corresponding to these fragments (i.e., false hotspot of Ty1 integration). To minimize PCR artifact, only one read among the duplicated reads (same orientation, same start, and end position) is therefore retained for further analysis. 


\section{CONCLUDING REMARKS}

HTS can provide valuable data to identify TE target-site preferences. However, it is essential to get high-quality de novo insertions DNA libraries in order to perform thorough and conclusive bioinformatics analysis. Every step in the library preparation has to be checked and validated before starting downstream processes. Here, we have described our procedure to map genome-wide Ty1 integration sites. We chose to select for de novo Ty1 insertion events based on the RIG his3AI. Yet, the necessity to express the HIS3 gene upon integration may favor selection of insertions in open chromatin. However, this bias should be marginal since there is no significant difference in integration profiles from unselected and selected Ty1 de novo insertion events in wild-type strains (Baller et al., 2012; Mularoni et al., 2012). In addition, in the absence of AC40/integrase interaction, we recovered de novo Ty1HIS3 insertion events in chromosome ends, which are poorly enriched in euchromatin, indicating that new targets can be identified by selecting $\mathrm{His}^{+}$cells (Bridier-Nahmias et al., 2015). Nevertheless, we cannot exclude that some mutants may massively redirect Ty1 integration to heterochromatic regions, where HIS3 might be silenced. Thus, future development will be to create libraries of de novo insertion events without any selection bias. Likewise, using diploid cells instead of haploid cells would be relevant when working with mutants to recover potential de novo insertions into essential genes. Combined together, these modifications should permit to recover all Ty1 de novo insertion events.

Previously, Chatterjee et al. added random tags in Tf1 in order to discriminate between true Tf1-independent integration events from clonal expansion or PCR amplification artifacts in the library (Chatterjee et al., 2014). Using random tags is not straightforward in the case of Ty1 because the LTR contains GAG sequences that need to be conserved at the amino acids levels. One possibility might be to add random tags in U3 of the $3^{\prime}$ LTR, which will be copied in the $5^{\prime}$ LTR by reverse transcription but should not impair HIS3 expression upon Ty1HIS3 integration.

Finally, we would like to emphasize that assaying Ty1 integration frequency before starting the whole procedure is crucial. It is not only important to determine the number of total cells to collect to get the right amount of $\mathrm{His}^{+}$cells, in a new yeast mutant or physiological context. It is also essential to highlight an important decrease in Ty1 integration frequency that might reveal a defect in step(s) of Ty1 replication upstream of integration. 
Different assays are already available to study Ty1 transcription, translation, and reverse transcription (Curcio et al., 2014). In this case, genome-wide mapping of de novo insertions might not be necessary.

\section{ACKNOWLEDGMENTS}

We are grateful to Jill Keeney and Amandine Bonnet for their constructive comments on the manuscript.

P.L. acknowledges support from intramural funding from Centre National de la Recherche Scientifique-CNRS, the Université Paris Diderot and the Institut National de la Santé et de la Recherche Médicale-INSERM, and from grants from the Fondation ARC pour la Recherche sur le Cancer (PJA 20151203412), the Agence Nationale de la Recherche through the initiatives d'excellence (Idex ANR-11-IDEX-0005-02), the Labex Who am I (ANR11-LABX-0071), and the generic call projects ANR-13-BSV30012 and ANR-17-CE11-0025. A.A.-L. is supported by a postdoctoral fellowship from Fondation pour la Recherche Médicale (SPF20170938755) and A.B. by Ph.D. fellowships from the Ministère de l'Enseignement Supérieur et de la Recherche and by Fondation pour la Recherche Médicale.

\section{REFERENCES}

Adams, A., Gottschling, D. E., Kaiser, C. A., \& Stearns, T. (1997). Methods in yeast genetics: A cold spring harbor laboratory course manual. Cold Spring Harbor, NY: Cold Spring Harbor Laboratory Press.

Bachmann, N., Eby, Y., \& Boeke, J. D. (2004). Local definition of Ty1 target preference by long terminal repeats and clustered tRNA genes. Genome Research, 14(7), 1232-1247. https://doi.org/10.1101/gr.2052904.

Baller, J. A., Gao, J., Stamenova, R., Curcio, M. J., \& Voytas, D. F. (2012). A nucleosomal surface defines an integration hotspot for the Saccharomyces cerevisiae Ty1 retrotransposon. Genome Research, 22(4), 704-713. https://doi.org/10.1101/ gr.129585.111.

Baller, J. A., Gao, J., \& Voytas, D. F. (2011). Access to DNA establishes a secondary target site bias for the yeast retrotransposon Ty5. Proceedings of the National Academy of Sciences of the United States of America, 108(51), 20351-20356. https://doi.org/10.1073/pnas. 1103665108.

Behrens, R., Hayles, J., \& Nurse, P. (2000). Fission yeast retrotransposon Tf1 integration is targeted to $5^{\prime}$ ends of open reading frames. Nucleic Acids Research, 28(23), 4709-4716. https://doi.org/10.1093/nar/28.23.4709.

Boeke, J. D., Garfinkel, D. J., Styles, C. A., \& Fink, G. R. (1985). Ty elements transpose through an RNA intermediate. Cell, 40(3), 491-500. https://doi.org/10.1016/00928674(85)90197-7.

Boeke, J. D., LaCroute, F., \& Fink, G. R. (1984). A positive selection for mutants lacking 5' phosphate decarboxylase activity in yeast: 5 Fluoro-orotic acid resistance. Molecular and General Genetics, 197, 345-346.

Brachmann, C. B., Davies, A., Cost, G. J., Caputo, E., Li, J., Hieter, P., et al. (1998). Designer deletion strains derived from Saccharomyces cerevisiae S288C: A useful set of strains and plasmids for PCR-mediated gene disruption and other applications. Yeast, 14(2), 115-132. https://doi.org/10.1002/(SICI)1097-0061(19980130)14:2< 115::AID-YEA204>3.0.CO;2-2. 
Bridier-Nahmias, A., Tchalikian-Cosson, A., Baller, J. A., Menouni, R., Fayol, H., Flores, A., et al. (2015). An RNA polymerase III subunit determines sites of retrotransposon integration. Science, 348(6234), 585-588. https://doi.org/10.1126/science. 1259114.

Chalker, D. L., \& Sandmeyer, S. B. (1990). Transfer RNA genes are genomic targets for de novo transposition of the yeast retrotransposon Ty3. Genetics, 126(4), 837-850. https:// doi.org/10.1146/annurev.ge.24.120190.002423.

Chatterjee, A. G., Esnault, C., Guo, Y., Hung, S., McQueen, P. G., \& Levin, H. L. (2014). Serial number tagging reveals a prominent sequence preference of retrotransposon integration. Nucleic Acids Research, 42(13), 8449-8460. https://doi.org/10.1093/nar/gku534.

Chuong, E. B., Elde, N. C., \& Feschotte, C. (2016). Regulatory evolution of innate immunity through co-option of endogenous retroviruses. Science, 351(6277), 1083-1087.

Curcio, M. J., \& Garfinkel, D. J. (1991). Single-step selection for Ty1 element retrotransposition. Proceedings of the National Academy of Sciences of the United States of America, 88(3), 936-940. https://doi.org/10.1073/pnas.88.3.936.

Curcio, M. J., \& Garfinkel, D. J. (1994). Heterogeneous functional Ty1 elements are abundant in the Saccharomyces cerevisiae genome. Genetics, 136(4), 1245-1259. https:// doi.org/10.1042/BJ20030755.

Curcio, M. J., Lutz, S., \& Lesage, P. (2014). The Ty1 LTR-retrotransposon of budding yeast, Saccharomyces cerevisiae. Mobile DNA, 927-964. https://doi.org/10.1128/ microbiolspec.MDNA3-0053-2014.

Dakshinamurthy, A., Nyswaner, K. M., Farabaugh, P. J., \& Garfinkel, D. J. (2010). BUD22 affects Ty1 retrotransposition and ribosome biogenesis in Saccharomyces cerevisiae. Genetics, 185(4), 1193-1205. https://doi.org/10.1534/genetics.110.119115.

Devine, S. E., \& Boeke, J. D. (1996). Integration of the yeast retrotransposon Ty1 is targeted to regions upstream of genes transcribed by RNA polymerase III. Genes and Development, 10(5), 620-633. https://doi.org/10.1101/gad.10.5.620.

Gai, X., \& Voytas, D. F. (1998). A single amino acid change in the yeast retrotransposon Ty5 abolishes targeting to silent chromatin. Molecular Cell, 1(7), 1051-1055. https://doi.org/ 10.1016/S1097-2765(00)80105-7.

Guo, Y., \& Levin, H. L. (2010). High-throughput sequencing of retrotransposon integration provides a saturated profile of target activity in Schizosaccharomyces pombe. Genome Research, 20(2), 239-248. https://doi.org/10.1101/gr.099648.109.

Hickey, A., Esnault, C., Majumdar, A., Chatterjee, A. G., Iben, J. R., McQueen, P. G., et al. (2015). Single-nucleotide-specific targeting of the Tf1 retrotransposon promoted by the DNA-binding protein sap1 of Schizosaccharomyces pombe. Genetics, 201(3), 905-924. https://doi.org/10.1534/genetics.115.181602.

Jacobs, J. Z., Rosado-Lugo, J. D., Cranz-Mileva, S., Ciccaglione, K. M., Tournier, V., \& Zaratiegui, M. (2015). Arrested replication forks guide retrotransposon integration. Science (New York, N.Y.), 349(6255), 1549-1553. https://doi.org/10.1126/science.aaa3810.

Ji, H., Moore, D. P., Blomberg, M. A., Braiterman, L. T., Voytas, D. F., Natsoulis, G., et al. (1993). Hotspots for unselected Ty1 transposition events on yeast chromosome III are near tRNA genes and LTR sequences. Cell, 73(5), 1007-1018. https://doi.org/10. 1016/0092-8674(93)90278-X.

Levin, H. L., \& Moran, J. V. (2011). Dynamic interactions between transposable elements and their hosts. Nature Reviews. Genetics, 12(9), 615-627. https://doi.org/10.1038/nrg3030.

Li, H., \& Durbin, R. (2009). Fast and accurate short read alignment with Burrows-Wheeler transform. Bioinformatics, 25(14), 1754-1760. https://doi.org/10.1093/bioinformatics/ btp324.

Morillon, A., Springer, M., \& Lesage, P. (2000). Activation of the Kss1 invasive-filamentous growth pathway induces Ty1 transcription and retrotransposition in Saccharomyces cerevisiae. Molecular and Cellular Biology, 20(15), 5766-5776. https://doi.org/10.1128/ MCB.20.15.5766-5776.2000. 
Mou, Z., Kenny, A. E., \& Curcio, M. J. (2006). Hos2 and Set3 promote integration of Ty1 retrotransposons at tRNA genes in Saccharomyces cerevisiae. Genetics, 172(4), 2157-2167. https://doi.org/10.1534/genetics.105.054072.

Mularoni, L., Zhou, Y., Bowen, T., Gangadharan, S., Wheelan, S. J., \& Boeke, J. D. (2012). Retrotransposon Ty1 integration targets specifically positioned asymmetric nucleosomal DNA segments in tRNA hotspots. Genome Research, 22(4), 693-703. https://doi.org/ 10.1101/gr.129460.111.

Nyswaner, K. M., Checkley, M. A., Yi, M., Stephens, R. M., \& Garfinkel, D. J. (2008). Chromatin-associated genes protect the yeast genome from Ty1 insertional mutagenesis. Genetics, 178(1), 197-214. https://doi.org/10.1534/genetics.107.082602.

Qi, X., Daily, K., Nguyen, K., Wang, H., Mayhew, D., Rigor, P., et al. (2012). Retrotransposon profiling of RNA polymerase III initiation sites. Genome Research, 22(4), 681-692. https://doi.org/10.1101/gr.131219.111.

Qi, X., \& Sandmeyer, S. (2012). In vitro targeting of strand transfer by the Ty3 retroelement integrase. Journal of Biological Chemistry, 287(22), 18589-18595. https://doi.org/10. 1074/jbc.M111.326025.

Sultana, T., Zamborlini, A., Cristofari, G., \& Lesage, P. (2017). Integration site selection by retroviruses and transposable elements in eukaryotes. Nature Reviews. Genetics, 18(5), 292-308. https://doi.org/10.1038/nrg.2017.7.

Van Dijk, E. L., Jaszczyszyn, Y., \& Thermes, C. (2014). Library preparation methods for next-generation sequencing: Tone down the bias. Experimental Cell Research, 322(1), 12-20. https:// doi.org/10.1016/j.yexcr.2014.01.008.

Winston, F., Durbin, K. J., \& Fink, G. R. (1984). The SPT3 gene is required for normal transcription of ty elements in S. cerevisiae. Cell, 39(3 Pt. 2), 675-682. https://doi. org/10.1016/0092-8674(84)90474-4.

Xie, W., Gai, X., Zhu, Y., Zappulla, D. C., Sternglanz, R., \& Voytas, D. F. (2001). Targeting of the yeast Ty5 retrotransposon to silent chromatin is mediated by interactions between integrase and Sir4p. Molecular and Cellular Biology, 21(19), 6606-6614. https://doi.org/10.1128/MCB.21.19.6606-6614.2001.

Zou, S., Ke, N., Kim, J. M., \& Voytas, D. F. (1996). The Saccharomyces retrotransposon Ty5 integrates preferentially into regions of silent chromatin at the telomeres and mating loci. Genes and Development, 10(5), 634-645. https://doi.org/10.1101/gad.10.5.634.

Zou, S., Kim, J. M., \& Voytas, D. F. (1996). The Saccharomyces retrotransposon Ty5 influences the organization of chromosome ends. Nucleic Acids Research, 24(23), 4825-4831. http://doi.org/6e0307. 